
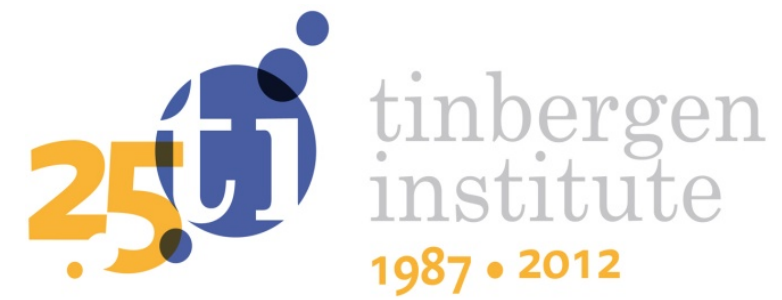

\title{
What can the Big Five Personality Factors contribute to explain Small-Scale Economic Behavior?
}

\author{
Julia Mü/ler \\ Christiane Schwieren ${ }^{2}$
}

1 Erasmus School of Economics, Erasmus University Rotterdam, and Tinbergen Institute;

2 University of Heidelberg. 
Tinbergen Institute is the graduate school and research institute in economics of Erasmus University Rotterdam, the University of Amsterdam and VU University Amsterdam.

More TI discussion papers can be downloaded at http://www.tinbergen.nl

Tinbergen Institute has two locations:

Tinbergen Institute Amsterdam

Gustav Mahlerplein 117

1082 MS Amsterdam

The Netherlands

Tel.: +31(0)205251600

Tinbergen Institute Rotterdam

Burg. Oudlaan 50

3062 PA Rotterdam

The Netherlands

Tel.: +31(0)10 4088900

Fax: $+31(0) 104089031$

Duisenberg school of finance is a collaboration of the Dutch financial sector and universities, with the ambition to support innovative research and offer top quality academic education in core areas of finance.

DSF research papers can be downloaded at: http://www.dsf.nl/

Duisenberg school of finance

Gustav Mahlerplein 117

1082 MS Amsterdam

The Netherlands

Tel.: +31(0)20 5258579 


\title{
WHAT CAN THE BIG FIVE PERSONALITY FACTORS CONTRIBUTE TO EXPLAIN SMALL-SCALE ECONOMIC BEHAVIOR?
}

\author{
JULIA MÜLLER \\ Erasmus University Rotterdam \& Tinbergen Institute \\ CHRISTIANE SCHWIEREN \\ University of Heidelberg
}

\begin{abstract}
Growing interest in using personality variables in economic research leads to the question whether personality as measured by psychology is useful to predict economic behavior. Is it reasonable to expect values on personality scales to be predictive of behavior in economic games? It is undoubted that personality can influence large-scale economic outcomes. Whether personality variables can also be used to understand micro-behavior in economic games is however less clear. We discuss reasons in favor and against this assumption and test in our own experiment, whether and which personality factors are useful in predicting behavior in the trust or investment game. We can also use the trust game to understand how personality measures fare relatively in predicting behavior when situational constraints vary in strength. This approach can help economists to better understand what to expect from the inclusion of personality variables in their models and experiments, and where further research might be useful and needed.
\end{abstract}

Keywords: Personality, Big Five, Five Factor Model, Incentives, Experiment, Trust Game.

JEL-Classifications: C72, C91, D03

E-mail addresses: jmuller@ese.eur.nl, christiane.schwieren@awi.uni-heidelberg.de.

Date: March 26, 2012.

Corresponding Author: Julia Müller, Erasmus School of Economics, H13-15, Erasmus University Rotterdam, PO Box 1738, 3000 DR Rotterdam, The Netherlands.

We would like to thank Ulrike Basten, Christian Fiebach, and Christine Stelzel for helpful comments and suggestions. Financial support from the START-Professorship of Heidelberg University, from the DFG Initiative of Excellence is gratefully acknowledged. 


\section{INTRODUCTION}

Recently, a growing interest among (behavioral) economists in personality variables can be observed (e.g., Almlund et al. (2011), Dohmen et al. (2010), Borghans et al. (2008)). In most published studies involving personality measures so far, the Big Five personality factors are used. Usually, correlations of the personality measures with some real-world aspects of economic behavior are reported and interpreted, for example with earnings or performance on the job. ${ }^{1}$ Researchers in experimental economics recently also started to include personality measures in experiments, hoping to be able to explain part of the behavioral heterogeneity found. Many studies relate some kind of Big Five personality variables, although measured by different instruments, to behavior in games like the Prisoner's dilemma, dictator, or ultimatum games (e.g., Brandstätter and Güth (2002), Ben-Ner et al. (2004a), Ben-Ner et al. (2004b), Swope et al. (2008)). Other studies use more specific scales, as locus of control, self-monitoring and sensation seeking (Boone et al. (1999)), or the Myers-Briggs Type Indicator (Schmitt et al. (2008)). Results of these exercises so far are not very conclusive.

One reason for this might lie in a methodological concern: Is it reasonable to expect values on personality scales to be predictive of micro-behavior in economic games? It is undoubted that personality can influence economic outcomes at large (Ozer and Benet-Martínez (2006)), such as occupational attainment (Filer (1985)) or occupational performance and success (Barrick and Mount (1991), Seibert and Kraimer (2001)). Whether personality variables can also be used to understand "micro"-behavior in economic games is however less clear.

In this paper, we discuss reasons in favor and against this assumption and test in our own experiment, whether personality factors are useful in predicting behavior in the trust game (Berg et al. (1995)). We can also use the trust game to understand how personality measures fare relatively in predicting behavior when situational constraints vary in strength.

The aim of this paper is exploratory, and due to this, our method is somewhat non-standard: We use the NEO-PI-R (Costa and McCrae (1992)) to measure the Big Five personality factors and link scores with behavior in a trust game, both of trustor and trustee. To find the relevant predictors we use in our regressions the method of backward stepwise elimination (Eid et al. (2010)). We do this on two levels - first, on the level of the five factors, and then also on the level of subscales. Here we follow an argument by Paunonen and Ashton (2001) who propose

\footnotetext{
${ }^{1}$ See for example Barrick and Mount (1991); Mueller and Plug (2006).
} 
to look at sub-scales (facets) as well for predicting behavior, because they are more specific and therefore more apt to explain small-scale behavior.

To preview our results, first, we can show that behavior of player 1 is more strongly determined by personality than behavior of player 2. Second, our analysis of subscale-correlations can tell us something about the trust-game in general. We discuss these results on the background of our aims, to get an idea of when personality matters and whether and how using personality as an additional explanatory variable is recommendable for (experimental) economists.

The remainder of the paper is structured as follows: In section 2, we give an overview of the literature on personality measurement. Then, we describe our experimental design (section 3) and the personality measures (section 3.2) used in more detail. Section 5.2 presents the results for player 1's behavior and section 5.3 those for player 2's behavior. Section 6 discusses the results and concludes.

\section{Measurement of Personality}

Personality psychology provides a large set of specific measures of potential interest for economists. On the one hand, there are general models of personality, comprising usually between four and seven general factors of personality (e.g., Goldberg (1981); Cloninger et al. (1993); Cattell and Schuerger (2003)). These are measured with different scales, varying in the content of the factors and the sub-factors measured. The most famous example is the NEO-PI-R measuring the so called Big Five Personality Factors (Costa and McCrae (1992)). On the other hand, there are more specific measures, capturing certain aspects of personality like anxiousness or aggressiveness. Here, we focus on the general measures and use the NEO-PI-R (Costa and McCrae (1992)), German: (Ostendorf and Angleitner (2004)) to measure the Big Five personality factors.

Researchers in personality psychology discuss whether personality factors can be expected to correlate strongly with real life outcomes and behavior, and whether it would be problematic if this were not the case. Since Mischel (1968), many personality psychologists argue that there is a ceiling of a correlation of .3 between personality variables and real life outcomes, the so called .3 barrier (Mischel (1968); see also McCrae (1982) for exceptions). Researchers that adhere to this ceiling argument put forward that the situation is at least as or more important in determining behavior and important life outcomes as is personality. Others (e.g., Ozer (1985)) however argue that .3-correlations are not so small and can have important practical effects and that most social, psychological (and even medical) 
variables, like socioeconomic status or cognitive ability do on average not correlate any stronger with important life outcomes. It is noteworthy that usually the outcomes studied are larger-life outcomes, such as divorce, occupational or educational attainment, and not "micro"-behaviors as trust-game behavior. An exception to this is research in organizational behavior that links, for example, locus of control or conscientiousness to individual performance, turnover decisions etc. (e.g., Judge and Bono (2001); Allen et al. (2005); Dudley et al. (2006)). Most researchers argue that personality influences outcomes in life not in a direct way, but rather affects general tendencies to act, e.g., to continue an education or to be persistent despite failures, which then influences the developmental path over the life span.

We therefore do not expect to be able to explain behavior in the trust game by a single personality factor. We do however think that if personality is indeed influencing behavior, it should at least contribute somewhat to an explanation of small-scale behavior, especially when the situation does not provide much guidance on how to behave.

\section{Experimental Design and Procedure}

The experiment was conducted in the experimental laboratory of SFB 504 in Mannheim. We had 138 subjects in total (57 male, 70 female, the remaining failed to indicate their sex). All subjects participated in two sessions with one week inbetween. The experiment consisted of 12 independent sessions in the first week and 12 sessions in the second week. In total, the experiment lasted for about one hour in the first and one hour in the second week. Subjects had filled in the personality questionnaires before our experimental sessions, which took them about 2 hours. We paid subjects at the very end of the experiment, i.e. after the session in the second week. Part of these earnings were performance-based, and part was fixed: both in week one and two they received a show-up fee of $€ 5$, and they received a fixed amount of $€ 14$ for filling in the personality questionnaires. The personality questionnaires were filed in on paper, while the games were programmed and conducted with the software z-tree (Fischbacher (2007)). All subjects were paid in cash and private. Subjects knew about the whole timing in advance. At the beginning of each session they received instructions containing the curse of events of the session. For each of the games and decisions instructions were distributed and also read aloud in each part by the experimenter, and participants had a chance to ask questions. 
3.1. The Trust Game. Players were randomly assigned to be either player 1, the trustor, or player 2, the trustee. Two players were randomly matched together. Both players got 10 units of an experimental currency. The trustor could first decide whether or not to send units to player 2 . If he sent $x$ units $(0<x \leq 10)$, these units got tripled. Then player 2 got informed about the amount she received and she could decide to send an amount $y(y \leq 10+3 x)$ back to player 1 (these units were not tripled). Therefore the payoffs for both players are determined by

$$
\text { player } 1: 10-x+y \quad \text { player } 2: 10+3 x-y \text {. }
$$

At the end of the experiment the experimental currency was transformed into Euro with an exchange rate of 1 Euro $=0.3 \mathrm{ECU}$.

3.2. The Big Five. To measure personality we use the five-factor model or the "Big Five" (Goldberg (1981), McCrae and Costa JR (2003))).

TABLE 1. The five factors and their facets (NEO-PI-R), acronyms in parenthesis

\begin{tabular}{ll}
\hline \hline Factor & Facets \\
Neuroticism $(N)$ & Anxiety $(N 1)$, Angry Hostility $(N 2)$, Depres- \\
& sion $(N 3)$, Self-Consciousness $(N 4)$, Impulsive- \\
& ness $(N 5)$, Vulnerability to Stress $(N 6)$ \\
& Warmth $(E 1)$, Gregariousness $(E 2)$, Assertive- \\
Extraversion $(E)$ & ness $(E 3)$, Activity $(E 4)$, Excitement-Seeking \\
& $(E 5)$, Positive Emotions $(E 6)$ \\
Openness to Experience $(O)$ & Fantasy $(O 1)$, Aesthetics $(O 2)$, Feelings $(O 3)$, \\
& Actions $(O 4)$, Ideas $(O 5)$, Values $(O 6)$ \\
Agreeableness $(A)$ & Trust $(A 1)$, Straightforwardness $(A 2)$, Altruism \\
& $(A 3)$, Compliance $(A 4)$, Modesty $(A 5)$, Tender- \\
& Mindedness $(A 6)$ \\
Conscientiousness $(C)$ & Competence $(C 1), \quad$ Order $(C 2)$, Dutiful- \\
& ness $(C 3)$, Achievement-Striving $(C 4)$, Self- \\
& Discipline $(C 5)$, Deliberation $(C 6)$ \\
\hline \hline
\end{tabular}

This model organizes personality traits in five basic dimensions: neuroticism, extraversion, openness to experience, agreeableness and conscientiousness. ${ }^{2}$ A list of the personality dimensions and their facets measured by the Big Five model can be found in table 1 .

${ }^{2}$ There are other labels for the five factors, we use the names by Costa and McCrae (1992). 
We use the NEO PI-R (Costa and McCrae (1992)), German version (Ostendorf and Angleitner (2004)). It consists of 241 items which have to be rated on a 5-point-Likert-scale.

\section{Behavioral Predictions}

As this paper is exploratory in character, we do not test specific hypotheses but rather explore how personality is related to behavior in the trust game. We did however formulate some rather general predictions that we will explain in the following. The basis for our predictions is on one hand the analysis of the situation both players in the trust game are in. On the other hand, we rely on the literature in personality psychology to predict which personality factors should be most important for behavior of player 1 and of player 2 in the trust game.

First, we focus on the link between personality factors and behavior, i.e. we discuss in what way a subject with a certain personality will behave in the trust game.

Neuroticism refers to the tendency to experience negative emotions and feelings, especially anxiety and general distress. Therefore we would expect that a person with high neuroticism-scores is rather anxious and avoids the risk of not getting money back.

Prediction 1. Higher levels on neuroticism will correlate with lower amounts sent by player 1 .

With respect to extraversion and openness to experience, we do not have clear-cut predictions regarding behavior in the trust game.

Agreeableness is defined as being compassionate and cooperative. It is linked to cooperative behavior (Volk et al. (2011); LePine and Van Dyne (2001)). This leads to the following intuitive prediction:

Prediction 2. Higher levels on agreeableness will correlate with higher amounts sent by player 1 and with higher relative amounts returned by player 2.

People high on conscientiousness act planned and not spontaneous, are dutiful and self-disciplined. Therefore we could imagine that high levels of conscientiousness will lead to higher amounts sent by player 1 (being dutiful) if a norm for sending is salient. As conscientiousness is also linked to rationality (D'Zurilla et al. (2011); Witteman et al. (2009)) high levels of conscientiousness could as well lead to lower amounts sent by player 1 (being more rational). For player 2, we assume the norm of reciprocity to be salient and thus, controlling for player 1's 
sending we expect trustors that are high on conscientiousness to follow this norm dutifully, and thus send back relatively more.

Prediction 3. Higher levels on conscientiousness of player 1 could lead to more or less sending. For player 2, we assume that high conscientiousness-scores lead to higher relative returns.

The reason to select the trust game for our research is that it contains two different situations (for player 1 and 2 respectively) that can be described in terms of a distinction often made in personality psychology: the distinction between weak and strong situations (Mischel (1977)). In weak situations, the behavioral triggers stemming from the situation are weak, and therefore personality variables can contribute significantly to an explanation of behavior. In strong situations on the contrary, situational triggers of behavior are strong and therefore personality variables will not contribute much to an explanation of behavior if player 1's behavior has been controlled for.

For player 2 in the trust game, the situation she finds herself in is relatively clearly determined: Player 1 has either trusted her with a certain amount of money or not, and now she has to decide how to react to this. As is known from the experimental literature, reciprocity is a strong norm prevailing in this context (e.g., Berg et al. (1995); McCabe et al. (1998); Fehr and Gächter (2000); McCabe et al. (2003)). Player 1 however faces a situation where norms or guidance for behavior are not that clear. Personal tendency to trust or to take risks will determine how much of the money he will send to player 2 .

Prediction 4. First players find themselves in a rather weak situation, therefore personality variables should contribute significantly to an explanation of behavior. Second players are in a rather strong situation, therefore personality variables should not contribute much to an explanation of behavior if player 1's behavior has been controlled for.

\section{Results}

5.1. Behavior in the Trust Game. Figure 1 shows the distribution of the amount sent by player 1 in the trust game.

60 subjects played the trust game in the role of player 1 , and the mean amount sent by player 1 is 4.3 . This is slightly below what is usually reported. Usual results are that player 1 sends on average half of his endowment and trust is not repaid by player 2 (e.g., Camerer (2003)). 


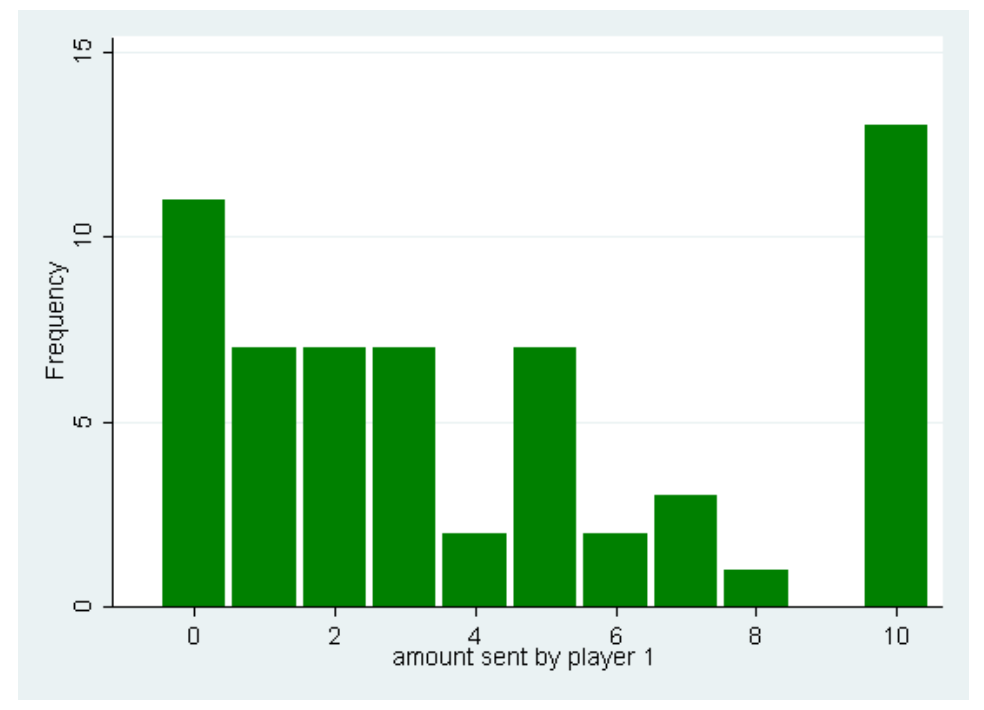

Figure 1. Trust - Amount Sent by Player 1

Returns show an absolute average of 5.9, and are strongly correlated with offers $(r=.736)$. Figures $2(\mathrm{a})$ shows absolute returns. The relation between the amount sent by player 1 and the amount returned by player 2 can be found in 2(b). The red line indicates where the amount sent is equal to the amount returned. Above the red line, trust is repaid by player 2 .

5.2. Personality measures and trustors behavior. Generally, we find reasonable variance in our personality scales ${ }^{3}$, even though one might assume at least with respect to some of the scales that a student population might be comparably homogeneous. Scores on all five of the personality measures are normally distributed (Kolmogorov-Smirnov test of normality).

As a first step to test our predictions we calculate correlations of first player behavior (and later second player behavior) with the personality factors. We report correlations in the first column of table 2. This table also shows intercorrelations of the personality measures.

As conjectured in predictions 1, 2 and 3, sending of player 1 correlates significantly negative with neuroticism, and significantly positive with agreeableness and conscientiousness.

Next we look at subscales (facets) and also calculate correlations here. We only report significant correlations.

We analyze the facets of the three factors that correlate with trustor behavior, neuroticism, agreeableness and conscientiousness. Anxiety (N1), angry hostility

\footnotetext{
${ }^{3}$ For descriptive statistics of the personality scales see table 7 in appendix B.1.
} 


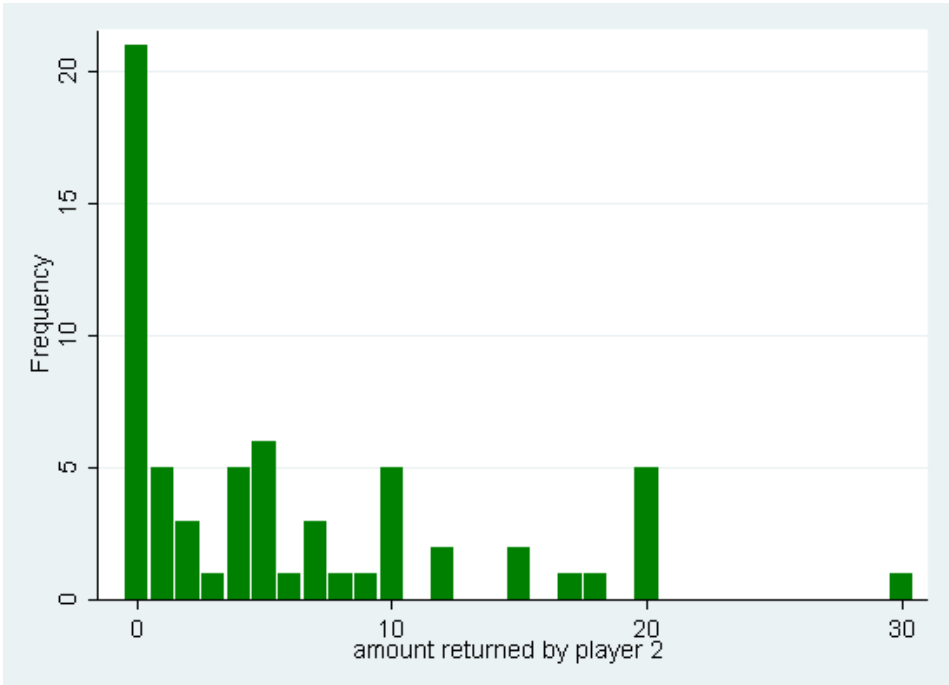

(a) Amount Returned by Player 2

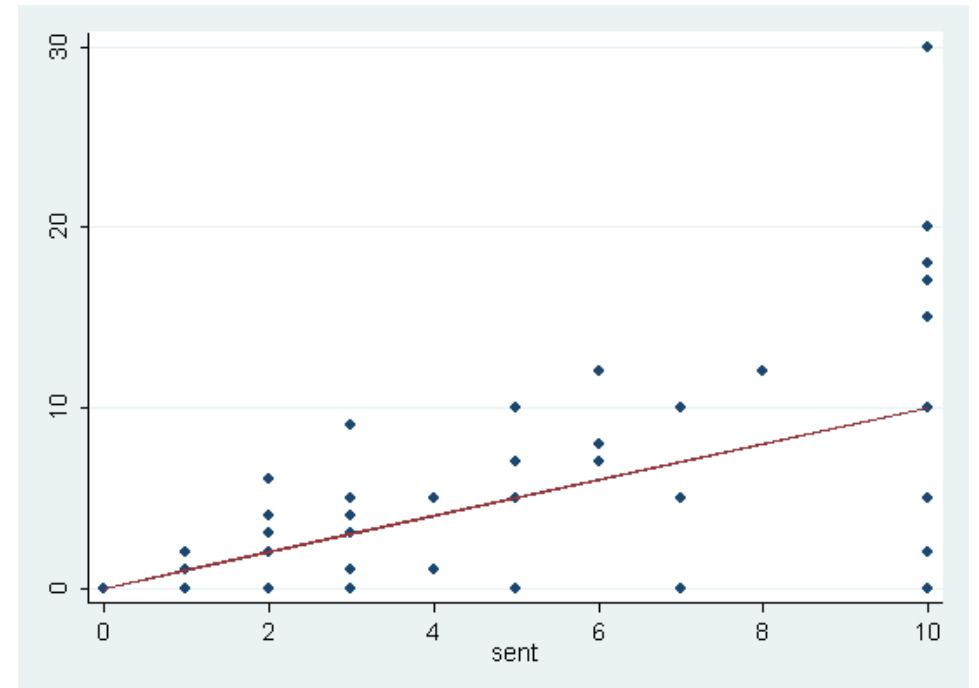

(b) Trustworthiness - Amounts sent and returned

(N2), and depression (N3) correlate significantly (negative) with sender behavior among the subscales of neuroticism. Of the subscales of agreeableness, trust $(A 1)$ correlates significantly positive with the amount sent by player 1 , and so does straightforwardness (A2).

Although having an intuitive appeal, altruism (A3) does not correlate with behavior of the trustor. There is a discussion in the literature about other motives than trust that are involved in trust game behavior; Cox (2004) points out that not only trust and trustworthiness, but also altruistic preferences can account for sending by player 1 or returning by player 2 . From the personality variables 
TABLE 2. Correlations between $x$, the amount sent by player 1 , and the personality factors

\begin{tabular}{|c|c|c|c|c|c|c|}
\hline & $x$ & $N$ & $E$ & $O$ & $A$ & $C$ \\
\hline \multirow[t]{2}{*}{$N$} & $-0.339^{* * *}$ & 1.000 & & & & \\
\hline & 0.009 & & & & & \\
\hline \multirow[t]{2}{*}{$E$} & -0.052 & $-0.331^{* *}$ & 1.000 & & & \\
\hline & 0.697 & 0.011 & & & & \\
\hline \multirow[t]{2}{*}{$O$} & 0.199 & -0.102 & $0.404^{* * *}$ & 1.000 & & \\
\hline & 0.134 & 0.446 & 0.002 & & & \\
\hline \multirow[t]{2}{*}{$A$} & $0.284^{* *}$ & -0.071 & 0.146 & 0.133 & 1.000 & \\
\hline & 0.031 & 0.596 & 0.274 & 0.318 & & \\
\hline \multirow[t]{2}{*}{$C$} & $-0.258^{*}$ & -0.210 & $0.233^{*}$ & 0.010 & -0.078 & 1.000 \\
\hline & 0.050 & 0.113 & 0.078 & 0.938 & 0.561 & \\
\hline
\end{tabular}

TABle 3 . Correlations between $x$, the amount sent by player 1 , and the personality facets of neuroticism, agreeableness, conscientiousness

\begin{tabular}{ll|cc}
\hline \hline & & $x$ & \\
\hline$N 1$ & Anxiety & $-0.377^{* * *}$ & $(0.003)$ \\
$N 2$ & Angry Hostility & $-0.319^{* *}$ & $(0.015)$ \\
$N 3$ & Depression & $-0.280^{* *}$ & $(0.033)$ \\
$N 4$ & Self-Consciousness & -0.211 & $(0.111)$ \\
$N 5$ & Impulsiveness & -0.078 & $(0.559)$ \\
$N 6$ & Vulnerability to Stress & -0.123 & $(0.358)$ \\
\hline$A 1$ & Trust & $0.370^{* * *}$ & $(0.004)$ \\
$A 2$ & Straightforwardness & $0.314^{* *}$ & $(0.016)$ \\
$A 3$ & Altruism & 0.167 & $(0.210)$ \\
$A 4$ & Compliance & 0.150 & $(0.262)$ \\
$A 5$ & Modesty & -0.007 & $(0.958)$ \\
$A 6$ & Tender-Mindedness & 0.172 & $(0.197)$ \\
\hline$C 1$ & Competence & 0.048 & $(0.720)$ \\
$C 2$ & Order & $-0.343^{* *}$ & $(0.008)$ \\
$C 3$ & Dutifulness & -0.128 & $(0.340)$ \\
$C 4$ & Achievement-Striving & $-0.243^{*}$ & $(0.066)$ \\
$C 5$ & Self-Discipline & -0.203 & $(0.126)$ \\
$C 6$ & Deliberation & $-0.260^{* *}$ & $(0.049)$
\end{tabular}


involved in player 1's decision, only trust, but not altruism has an influence on the amount sent by the first player.

Of the subscales of conscientiousness, order $(C 2)$, achievement-striving $(C 4)$ and deliberation $(C 6)$ correlate significantly negative with the amount sent by player 1 .

After presenting first results we turn to the regression analysis.

Here, we use a modeling approach that is often used in exploratory studies (e.g., Eid et al. (2010)): Backward stepwise elimination of insignificant predictors. In the first step we include all predictors that correlate with behavior of player 1 and some control variables in a regression. We then stepwise eliminate always the least significant predictor until we get a model that consists only of significant predictor variables. This exploratory way of modeling is indicated in our case as most of the personality variables we study are inter-correlated. A model including all potentially relevant personality variables therefore underestimates the explanatory power of each of the variables, due to multicollinearity. By doing a step-wise elimination of insignificant predictors, we reach a model where only the most inclusive and important personality variables remain.

For the trustor we explain the amount sent in two different ways using the Big Five personality variables: in the first approach we use the factors correlating individually with the behavior of the first player (table 2) and in the second approach we use the facets of these factors, and again only the facets correlating individually with the behavior of the first player (table 3).

Table 4 shows all four models (model I and II - factor-approach, model III and IV - facet-approach). In model I, the factors neuroticism, agreeableness, and conscientiousness, together with the controls are included, stepwise elimination leads to model II. In both models neuroticism and conscientiousness have a significant negative impact on the amount sent and agreeableness a significant positive impact. These models explain $23 \%$ to $24 \%$ of the variance in the amount sent by the first player. Using facets, there are no significant predictors in model III. In model VI, all insignificant predictors have been excluded, significant predictors are anxiety $(N 1)$, trust $(A 1)$, and order $(C 2)$ again signed as before: a negative impact of the neuroticism- and conscientiousness-facets and a positive impact of the agreeableness-facet. This model explains a slightly larger part of the variance in player 1's behavior than the factor-models, around $26 \%$. 
TABLE 4 . Regression on $x$, the amount sent by player 1

\begin{tabular}{|c|c|c|c|c|}
\hline Variable & model I & model II & model III & model IV \\
\hline \multirow[t]{2}{*}{$N$} & $-0.400^{* * *}$ & $-0.390^{* * *}$ & & \\
\hline & $(0.024 / 0.004)$ & $(0.021 / 0.002)$ & & \\
\hline \multirow[t]{2}{*}{ N1 } & & & -0.232 & $-0.260^{* *}$ \\
\hline & & & $(0.125 / 0.211)$ & $(0.082 / 0.034)$ \\
\hline \multirow[t]{2}{*}{ N2 } & & & 0.024 & \\
\hline & & & $(0.130 / 0.890)$ & \\
\hline \multirow[t]{2}{*}{ N3 } & & & -0.068 & \\
\hline & & & $(0.132 / 0.718)$ & \\
\hline \multirow[t]{2}{*}{$A$} & $0.246^{* *}$ & $0.231^{*}$ & & \\
\hline & $(0.024 / 0.043)$ & $(0.023 / 0.052)$ & & \\
\hline \multirow[t]{2}{*}{$A 1$} & & & 0.208 & $0.281^{* *}$ \\
\hline & & & $(0.116 / 0.174)$ & $(0.091 / 0.021)$ \\
\hline \multirow[t]{2}{*}{ A2 } & & & 0.202 & \\
\hline & & & $(0.108 / 0.136)$ & \\
\hline \multirow[t]{2}{*}{$C$} & $-0.353^{* * *}$ & $-0.323^{* * *}$ & & \\
\hline & $(0.020 / 0.007)$ & $(0.019 / 0.009)$ & & \\
\hline \multirow[t]{2}{*}{$C^{2} 2$} & & & -0.240 & $-0.277^{* *}$ \\
\hline & & & $(0.099 / 0.115)$ & $(0.077 / 0.020)$ \\
\hline \multirow[t]{2}{*}{$C_{4}$} & & & -0.050 & \\
\hline & & & $(0.123 / 0.768)$ & \\
\hline \multirow[t]{2}{*}{$C 6$} & & & -0.016 & \\
\hline & & & $(0.108 / 0.921)$ & \\
\hline \multirow[t]{2}{*}{ age } & -0.116 & & -0.136 & \\
\hline & $(0.108 / 0.331)$ & & $(0.110 / 0.271)$ & \\
\hline \multirow[t]{2}{*}{$\operatorname{sex}$} & -0.043 & & 0.001 & \\
\hline & $(0.970 / 0.745)$ & & $(0.997 / 0.990)$ & \\
\hline $\mathrm{n}$ & 58 & 58 & 58 & 58 \\
\hline$R^{2}$ & 0.2962 & 0.2814 & 0.3472 & 0.2972 \\
\hline $\operatorname{adj} . R^{2}$ & 0.2286 & 0.2414 & 0.2083 & 0.2581 \\
\hline
\end{tabular}

Note: beta, SE/p-value in parenthesis; *, **, *** indicate significance at the $10 \%, 5 \%$ and $1 \%$ level respectively.

Anxiety is defined ${ }^{4}$ as the level of free floating anxiety and has been linked to risk averse behavior in different domains ${ }^{5}$, so it is intuitive that this facet has a negative impact on the amount sent by player 1. Order is the degree of personal

\footnotetext{
${ }^{4}$ All facet-definitions following Costa and McCrae (1992).

${ }^{5}$ Nicholson et al. (2005) analyze personality and risk propensity in different domains and find anxiety being linked to less risk taking in recreation, career, and safety.
} 
organization and has also a negative impact on the amount sent by player 1 . The positive influence of trust highlights again that the trust game is indeed about trust: trust being defined as the belief in the sincerity and good intentions of others has a positive impact on the amount sent by player 1 .

5.3. Trustee Behavior. We now turn to the behavior of the second player. As described before, there is one clear difference between predicting first player's behavior and predicting second player's behavior: behavior of player 2 will most probably be guided by reciprocal incentives, i.e., what the first player has sent to the second player will matter. We thus have a strong situation here, as opposed to the weak situation in which first players find themselves in. In line with the general search for interactions of personality variables and the environment in personality psychology, our main question is whether personality variables predict beyond "material", situational characteristics, or whether it is only player 1's behavior that predicts the responses of player 2 .

We start again with correlations. If we take data of all trustees, the only and highly significant predictor of player 2's behavior is the amount player 1 sent to her $(0.731, p=0.000)$, we find no correlation at all between behavior of player 2 and any of the personality factors or of the sub-factors, i.e., the situation determines behavior stronger than do personality variables.

TABLE 5. Regression on $y$, the amount returned by player 2

\begin{tabular}{|c|c|c|}
\hline Variable & model I & model II \\
\hline \multirow[t]{2}{*}{ sent } & $0.737^{* * *}$ & $0.731^{* * *}$ \\
\hline & $(0.169 / 0.000)$ & $(0.160 / 0.000)$ \\
\hline \multirow[t]{2}{*}{ Sex } & -0.56 & \\
\hline & $(1.322 / 0.546)$ & \\
\hline \multirow[t]{2}{*}{ Age } & 0.049 & \\
\hline & $(0.280 / 0.592)$ & \\
\hline $\mathrm{n}$ & 61 & 64 \\
\hline$R^{2}$ & 0.540 & 0.534 \\
\hline $\operatorname{adj} . R^{2}$ & 0.516 & 0.527 \\
\hline $\begin{array}{l}\text { Note: beta } \\
\text { indicate sig } \\
\text { respectively }\end{array}$ & $\begin{array}{l}\mathrm{SE} / \mathrm{p} \text {-value in } \\
\text { ificance at the }\end{array}$ & $\begin{array}{l}\text { nthesis; } * * \\
5 \% \text { and } 1 \%\end{array}$ \\
\hline
\end{tabular}


Including these variables in a regression on the return of player 2 , the results in table 5 again highlight that only the amount that player 1 has sent to player 2 explains the amount player 2 returns. ${ }^{6}$

In an attempt to give personality variables the best opportunity to have an effect, we look at only part of our sample, namely those second players who received high offers in the trust game, where high offers are defined ${ }^{7}$ as offers of at least five. We are aware of the fact that analyzing this sub-sample leads to a small number of observations, but due to the exploratory character of this study we still do this analysis.

As expected, personality factors have some influence on behavior in the case where player 1's sending has been reasonable and fair: On the factor-level we still find no correlations, but on facet-level modesty $(A 5)$ correlates negatively with the amount returned $(-0.415, p=0.035)$, while competence $(C 1)$ correlates positive $(0.399, p=0.044)$.

A positive relationship between a conscientiousness-facet is in line with prediction 3. This is also generally coherent with the definition of conscientiousness being defined as the degree of organization, control and goal directed behavior. The facet competence measures the belief in own self efficacy which could intuitively be linked to higher amounts returned. Someone believing in his self efficacy may takes things into his own hands, that is returns higher amounts. In contrast, a negative relationship between modesty and the amount return is very unintuitive. Modesty is defined as a tendency to play down own achievements and be humble. Because of the small sample size we had a closer look at this result. A visual inspection and detection of extremes demonstrated that some subjects with low scores on modesty returned very high amounts. Analyzing these observations more detailed we declared two of the observations as outliers. After dropping these two observations there is no longer a significant correlation between modesty and the amount returned. Therefore, modesty is not included into the regression (see table 6).

Including the facet competence in a regression together with the amount sent by the first player and controls for age and sex, in the full model again only the amount sent is significant, and $17 \%$ of the variance is explained, while after step-wise exclusion of insignificant predictors, the amount sent by the first player

\footnotetext{
${ }^{6}$ Sometimes it is argued that one should only analyze those second players that received positive amounts from the first player, because players receiving zero are forced to sent back zero. Repeating our analysis only with subjects that received strictly positive amounts we find structurally the same results as in table 5 .

${ }^{7}$ This definition of high conveys the definition of Blanco et al. (2011) for high offers in an ultimatum game.
} 
TABLE 6. Only for high amounts received: regression on $y$, the amount returned by player 2

\begin{tabular}{lcc}
\hline \hline Variable & model I & model II \\
\hline sent & $0.449^{* *}$ & $0.497^{* *}$ \\
& $(0.776 / 0.048)$ & $(0.561 / 0.004)$ \\
$C 1$ & 0.222 \\
& $(0.436 / 0.311)$ \\
Sex & -0.063 \\
\multicolumn{4}{c}{$(3.140 / 0.756)$} \\
Age & 0.090 \\
\multicolumn{4}{c}{$(0.507 / 0.646)$} \\
$\mathrm{n}$ & 25 \\
$R^{2}$ & 0.310 & 31 \\
adj. $R^{2}$ & 0.172 & 0.247 \\
\hline Note: beta, & SE/p-value in parenthesis; ***, *** \\
indicate significance at the $10 \%, 5 \%$ and $1 \%$ level \\
respectively.
\end{tabular}

remains the only significant predictor in the model, and the model explains $22 \%$ of the variance.

So even in this case where we gave personality its best chance: the situation determines behavior.

\section{Discussion}

To answer the question to what extent personality can contribute to explain small-scale economic behavior we decided to use the trust game as an example.

There are other studies relating the trust game or trust in general to personality. Two studies relate the Machiavellian personality test to the trust game: Gunnthorsdottir et al. (2002) use a modified trust game and Burks et al. (2003) the standard trust game. Having hypotheses about both trust and trustworthiness, related to scoring high on Machiavellism, Gunnthorsdottir et al. (2002) find that subjects high on Machiavellism are less trustworthy, where Burks et al. (2003) find that high Machiavellism predicts lack of trust, but not trustworthiness.

Fahr and Irlenbusch (2008) use the Big Five personality model, measured by Catell's 16 PF-R, to analyze trust between representatives of organizations. To study this question they use a modified trust game. To implement their organizational setting players were in groups of four and had to decide as a representative of their own group. They found a link between anxiety, being linked to risk averse 
behavior, and trustor behavior and anxiety, on the other hand being liked to cooperative behavior, to trustee's decision. Our study strengthens the result that anxiety is linked to distrust. Using another measure of the Big Five and the standard trust game we find that trust is negatively related to anxiety (see table $4)$.

The research focus of Ben-Ner and Halldorsson (2010) concentrates on understanding trusting and trustworthiness. They use many different measures, and among others the Big Five factors (measured by the NEO-FFI), but to define trust and trustworthiness they use on the one hand survey questions and on the other hand a modified trust game (a repeated variant).

Our exploratory study had two main aims: First, we wanted to test whether personality variables can be used to predict "micro"-level behavior in economic games, where we use the example of the trust game. Next, we hypothesized that strong situations allow for less influence of personality factors than weak situations, and that first players in a trust game are in a weak situation, while second players face a strong situation.

Our results confirm most of our general and some of the more specific predictions: First, we do find that personality variables contribute to an explanation of behavior. Trustor behavior can be explained to a large extent using personality variables. This is good news especially for personality psychologists, who so far seldom validate their personality scales with the help of clear-cut behavioral experiments. It is also good news for all those experimental and behavioral economists that now start to use personality measures in their experiments. But, we also confirm the notion of strong and weak situations found in personality psychology: First player's behavior can be explained to a large extent (up to $26 \%$ of the variance) using personality variables, while second player's behavior is explained by the situation. This is essentially good news for standard economics, as this means that if incentives or behavioral norms are clear and strongly point into a specific direction, most people, independent of their personality, will react to these incentives, and predictably so. 


\section{REFERENCES}

David G. Allen, Kelly P. Weeks, and Karen R. Moffitt. Turnover intentions and voluntary turnover: the moderating roles of self-monitoring, locus of control, proactive personality, and risk aversion. The Journal of Applied Psychology, 90(5):980-90, September 2005.

Mathilde Almlund, Angela Lee Duckworth, James J. Heckman, and Tim D. Kautz. Personality psychology and economics. 2011.

Murray R. Barrick and Michael K. Mount. The Big Five personality dimensions and job performance: A meta-analysis. Personnel Psychology, 44:1-26, 1991.

Avner Ben-Ner and Freyr Halldorsson. Trusting and trustworthiness: What are they, how to measure them, and what affects them. Journal of Economic Psychology, 31(1):64-79, February 2010.

Avner Ben-Ner, Fanmin Kong, and Louis Putterman. Share and share alike? Intelligence, socialization, personality, and gender-pairing as determinants of giving. Journal of Economic Psychology, 25(5):581-589, 2004.

Avner Ben-Ner, Louis Putterman, Fanmin Kong, and Dan Magan. Reciprocity in a two-part dictator game. Journal of Economic Behavior \& Organization, 53(3):333-352, March 2004.

Joyce Berg, John Dickhaut, and Kevin A McCabe. Trust, reciprocity, and social history. Games and Economic Behavior, 10(1):122-142, 1995.

Mariana Blanco, Dirk Engelmann, and Hans Theo Normann. A within-subject analysis of other-regarding preferences. Games and Economic Behavior, 72:321338, 2011.

Christophe Boone, Bert De Brabander, and Arjen Van Witteloostuijn. The impact of personality on behavior in five Prisoner's Dilemma games. Journal of Economic Psychology, 20:343-377, 1999.

Lex Borghans, A. Duckworth, J.J. Heckman, and B. Ter Weel. The economics and psychology of personality traits. NBER Working Paper, (December), 2008.

Hermann Brandstätter and Werner Güth. Personality in dictator and ultimatum games. Central European Journal of Operations Research, 10(3):191-215, 2002.

Stephen V. Burks, Jeffrey P. Carpenter, and Eric Verhoogen. Playing both roles in the trust game. Journal of Economic Behavior \& Organization, 51(2):195-216, 2003.

Colin F. Camerer. Behavioral Game Theory. Princeton University Press, Princeton, New Jersey, 2003.

Heather E. P. Cattell and James M. Schuerger. Essentials of 16PF Assessment. Wiley, 2003. 
C. Robert Cloninger, Dragan M. Svrakic, and Thomas R. Przybeck. A Psychobiological Model of Temperament and character. Archieves of General Psychatry, 50(12):975-990, 1993.

Paul T. Costa and Robert R. McCrae. Revised NEO Personality Inventory (NEO$P I R$ ) and Neo Five Factor Inventory (NEO-FFI). Psychological Assessment Inventories, Odessa, 1992.

James C. Cox. How to identify trust and reciprocity. Games and Economic Behavior, 46(2):260-281, February 2004.

Thomas Dohmen, Armin Falk, D. Huffman, and U. Sunde. Are risk aversion and impatience related to cognitive ability? The American Economic Review, 100(3):1238-1260, 2010.

Nicole M. Dudley, Karin A. Orvis, Justin E. Lebiecki, and José M. Cortina. A meta-analytic investigation of conscientiousness in the prediction of job performance: examining the intercorrelations and the incremental validity of narrow traits. The Journal of Applied Psychology, 91(1):40-57, January 2006.

Thomas D. D'Zurilla, Alberto Maydeu-Olivares, and David Gallardo-Pujoi. Predicting social problem solving using personality traits. Personality and individual Differences, 50(2):142-147, 2011.

Michael Eid, Mario Gollwitzer, and Manfred Schmitt. Statistik und Forschungsmethoden: Lehrbuch. Beltz Verlag, Weinheim, Basel, 2010.

René Fahr and Bernd Irlenbusch. Identifying personality traits to enhance trust between organisations: an experimental approach. Managerial and Decision Economics, 29(6):469-487, September 2008.

Ernst Fehr and Simon Gächter. Fairness and Retaliation: The Economics of Reciprocity. Journal of Economic Perspectives, 14(3):159-182, August 2000.

Randall K. Filer. The role of personality and tastes in determining occupational structure. Industrial \& Labor Relations Review, 39(3):412-424, 1985.

Urs Fischbacher. z-Tree: Zurich toolbox for ready-made economic experiments. Experimental Economics, 10(2):171-178, February 2007.

Lewis R. Goldberg. Language and Individual Differences: The Search for Universals in Personality Lexicons. Review of personality and social psychology, 2:141-165, 1981.

Anna Gunnthorsdottir, Kevin McCabe, and Vernon Smith. Using the Machiavellianism instrument to predict trustworthiness in a bargaining game. Journal of Economic Psychology, 23(1):49-66, February 2002.

Timothy A. Judge and Joyce E. Bono. Relationship of core self-evaluations traitsself-esteem, generalized self-efficacy, locus of control, and emotional stabilitywith job satisfaction and job performance: A meta-analysis. Journal of Applied 
Psychology, 86(1):80-92, 2001.

Jeffrey A. LePine and Linn Van Dyne. Voice and cooperative behavior as contrasting forms of contextual performance: Evidence of differential relationships with Big Five personality characteristics and cognitive ability. Journal of Applied Psychology, 86(2):326-336, 2001.

Kevin A. McCabe, Stephen J. Rassenti, and Vernon L. Smith. Reciprocity, trust, and payoff privacy in extensive form bargaining. Games and Economic Behavior, 24(1-2):10-24, 1998.

Kevin A. McCabe, Mary L. Rigdon, and Vernon L. Smith. Positive reciprocity and intentions in trust games. Journal of Economic Behavior \& Organization, 52(2):267-275, October 2003.

Robert R. McCrae and Paul T. Costa JR. Personality in Adulthood, a Five-Factor Theory Perspective. Guilford Press, New York, 2003.

Robert R. McCrae. Consensual validation of personality traits: Evidence from selfreports and ratings. Journal of Personality and Social Psychology, 43(2):293303, 1982.

Walter Mischel. Personality and assessment. Wiley, New York, 1968.

Walter Mischel. The interaction of person and situation. In D. Magnussen and N.S. Endler, editors, Personality at the Crossroads: Current Issues in Interactional Psychology, pages 333-352, Hillsdale, NJ, 1977. Lawrence Erlbaum.

Gerrit Mueller and Erik Plug. Estimating the Effect of Personality on Male and Female Earnings. Industrial and Labor Relations Review, 60(1):3-22, 2006.

Nigel Nicholson, Mark Fenton O'Creevy, Emma Soane, and Paul Willman. Personality and domain-specific risk taking. Journal of Risk Research, 8:157-176, 2005.

Fritz Ostendorf and Alois Angleitner. NEO-Persönlichkeitsinventar nach Costa und McCrae, revidierte Fassung (NEO-PR-I). Hogrefe, Göttingen, 2004.

Daniel J. Ozer and Verónica Benet-Martínez. Personality and the prediction of consequential outcomes. Annual review of psychology, 57(8):401-21, January 2006.

Daniel J. Ozer. Correlation and the Coefficient of Determination. Psychological Bulletin, 97(2):307-315, 1985.

Sampo V. Paunonen and Michael C. Ashton. Big Five factors and facets and the prediction of behavior. Journal of Personality and Social Psychology, 81(3):524539, 2001.

David P. Schmitt, Anu Realo, Martin Voracek, and Jüri Allik. Why can’t a Man be More like a Woman? Sex Differences in Big Five Personality Traits Across 55 Cultures. Journal of personality and social psychology, 94(1):168-82, January 
2008.

Scott E. Seibert and Maria L. Kraimer. The Five-Factor Model of Personality and Career Success. Journal of Vocational Behavior, 58(1):1-21, February 2001.

Kurtis J. Swope, John Cadigan, Pamela M. Schmitt, and Robert Shupp. Personality preferences in laboratory economics experiments. Journal of SocioEconomics, 37(3):998-1009, 2008.

Stefan Volk, Christian Thöni, and Winifried Ruigrok. Personality, personal values and cooperation perferences in public goods games: A longitutinal study. Personality and individual Differences, 50(6):810-815, 2011.

Cilia Witteman, John van den Bercken, Laurence Claes, and Antonio Godoy. Assessing Rational and Intuitive Thinking Styles. European Journal of Psychological Assessment, 25(1):39-47, January 2009. 


\section{Appendix A. Trust Game}

Instructions. These instructions have been translated into English from the Original German.

In this game you will play together with one other person in the laboratory. You are either player $A$ or player $B$. This will be randomly determined by the computer. The other person $(A$ or $B)$ you will play together will also be randomly determined by the computer.

Both player $A$ and $B$ receive 10 experimental currency units (ECU). Player $A$ can decide whether he would like to sent taler to player $B$ and if so, how many (only integer amounts are possible). The amount of ECU that player $A$ sents to player $B$ is tripled. Therefore player $B$ receives 3 units for each unit sent by player $A$. Player $B$ can then decide whether she wants to return ECU to player $A$ and if so, how many. These units will not be tripled. This is the end of this game.

The experimental currency is converted into Euros as follows: $1 \mathrm{ECU}=0.30$ Euro.

If you now got questions regarding these instructions, raise your hand and one of the experimenters will come to answer your questions.

Appendix B. Big Five

TABle 7. Descriptive Statistics of the Personality Scales

\begin{tabular}{lccccc}
\hline \hline Variable & $\mathbf{n}$ & Mean & SD & Min & Max \\
Neuroticism & 126 & 91.985 & 23.666 & 27 & 155 \\
Extraversion & 126 & 116.020 & 21.564 & 32 & 158 \\
Openness & 126 & 124.478 & 16.781 & 72 & 180 \\
Agreeableness & 126 & 109.925 & 18.700 & 67 & 152 \\
Conscientiousness & 126 & 116.294 & 21.636 & 58 & 166 \\
\hline \hline
\end{tabular}

\section{B.1. Descriptive Statistics of the Personality Scales.}

\section{B.2. Factors and Facets.}


BIG FIVE AND SMALL-SCALE ECONOMIC BEHAVIOR

TABlE 8. Names of the Factors and Facets

\begin{tabular}{lll}
\hline \hline$N$ Neuroticism & $N 1$ & Anxiety \\
& $N 2$ & Angry Hostility \\
& $N 3$ & Depression \\
& $N 4$ & Self-Consciousness \\
& $N 5$ & Impulsiveness \\
& $N 6$ & Vulnerability to Stress \\
\hline$E$ Extraversion & $E 1$ & Warmth \\
& $E 2$ & Gregariousness \\
& $E 3$ & Assertiveness \\
& $E 4$ & Activity \\
& $E 5$ & Excitement-Seeking \\
& $E 6$ & Positive Emotions \\
\hline & $O 1$ & Fantasy \\
& $O 2$ & Aesthetics \\
& $O 3$ & Feelings \\
& $O 4$ & Actions \\
& $O 5$ & Ideas \\
& $O 6$ & Values \\
\hline \hline & $A 1$ & Trust \\
& $A 2$ & Straightforwardness \\
& $A 3$ & Altruism \\
& $A 4$ & Compliance \\
& $A 5$ & Modesty \\
& $A 6$ & Tender-Mindedness \\
\hline Agreeableness & $C 1$ & Competence \\
& $C 2$ & Order \\
& $C 3$ & Dutifulness \\
& $C 4$ & Achievement-Striving \\
& $C 5$ & Self-Discipline \\
& & \\
& &
\end{tabular}

